\title{
HEMA and Alginate-based chondrogenic semi- interpenetrated hydrogels: Synthesis and Biological Characterization
}

\section{María Luz Torres , Tamara G. Oberti \& Juan Manuel Fernández}

To cite this article: María Luz Torres , Tamara G. Oberti \& Juan Manuel Fernández (2020): HEMA and Alginate-based chondrogenic semi-interpenetrated hydrogels: Synthesis and Biological Characterization, Journal of Biomaterials Science, Polymer Edition, DOI: 10.1080/09205063.2020.1849920

To link to this article: https://doi.org/10.1080/09205063.2020.1849920

Accepted author version posted online: 12 Nov 2020.

Submit your article to this journal $\sqsubset$

山 Article views: 1

a

View related articles $\sqsubset$

View Crossmark data \lceil 
Running Heads: Characterization of HEMA and Alginate chondrogenic hydrogels

\title{
HEMA and Alginate-based chondrogenic semi-interpenetrated hydrogels: Synthesis and Biological Characterization
}

\author{
María Luz Torres ${ }^{1}$, Tamara G. Oberti ${ }^{2}$, Juan Manuel Fernández ${ }^{1, *}$ \\ ${ }^{1}$ Laboratorio de Investigaciones en Osteopatías y Metabolismo Mineral, Facultad de Ciencias \\ Exactas, Universidad Nacional de La Plata, 47 y 115 (1900), Argentina. \\ ${ }^{2}$ Instituto de Investigaciones Fisicoquímicas Teóricas y Aplicadas (INIFTA), Facultad de Ciencias \\ Exactas, UNLP, CONICET, CCT, Sucursal 4 Casilla de Correo 16, 1900, La Plata, Argentina.
}

*Corresponding author: jmfernandez@ biol.unlp.edu.ar

\begin{abstract}
:
Cartilage tissue engineering (CTE) has the general objective of restoring and improving damaged cartilage. A very interesting strategy of CTE is to combine different polymers to obtain a viscoelastic material. In the present study we have evaluated the applicability of Poly(2-hydroxyethyl methacrylate) networks semi-interpenetrated with sodium alginate for CTE. Alginate-containing hydrogels show an increase in scaffold porosity and swelling capacity, when compared with nonporous poly(2-hydroxyethyl methacrylate) scaffolds. Primary chondrocytes from young rats were cultured on the hydrogels, and an increase in chondrocyte proliferation and chondrocytic markers was observed in alginate-containing hydrogels. Chondrocytic phenotype was preserved on hydrogels containing the lowest amount of crosslinker and initiator (SEMI 3 and SEMI 4). In addition, Nitric oxide production by RAW264.7 macrophages grown on hydrogels was tested and none of the hydrogels showed high levels of this inflammatory marker after 2 days. These results indicate that our alginate-containing hydrogels could be useful for CTE.
\end{abstract}

Keywords: semi-interpenetrating polymer network, Chondrocyte, Chondrocompatibility, swelling, contact angle

\section{Introduction}

Unlike other tissues, cartilage is basically a neuronless tissue with low cellular concentration that lacks blood and lymphatic vessels. In the case of articular cartilage, its metabolism depends on the diffusion of nutrients and oxygen through the synovial fluid and the subchondral bone. Due to this, cells exhibit a slow anabolism and proliferative capacity, causing a decrease in their ability to rapidly self-repair [1-3].

Articular cartilage can be altered due to several causes such as age, trauma or inflammatory reactions leading to a decrease in the extracellular matrix and cell number. Damage to the cartilage associated with catabolic processes can lead to osteoarthritis, the most common of joint disorders [4]. This degeneration of cartilage affects between 25 and $30 \%$ of people of middle and old age, with increasing frequency due to the rise in life expectancy and obesity [2].

Currently, there are several techniques to treat cartilage defects such as abrasion, perforation, autograft and allograft, or implants of autologous chondrocytes [5, 6]. These therapies have different disadvantages such as calcifications or instability of the grafts [4]. 
Tissue engineering uses concepts from different disciplines (engineering, materials sciences, biology, medicine, among others) to design materials that improve and restore damaged tissue [7]. Hydrogels are a promising material to be used in cartilage tissue engineering, this is because they can have a swelling capacity similar to cartilage leading to a viscoelastic environment that facilitates the diffusion of nutrients [5]. Several types of polymers, both natural and synthetic, are being studied in order to obtain scaffolds that can be used for the repair of cartilage.

The extracellular matrix of cartilage contains hyaluronan, which has an important role in chondrocyte proliferation and differentiation [8]; thus, hyaluronan-like material should be studied for cartilage tissue engineering. Hyaluronan is a disaccharide composed of $\mathrm{N}$-acetylglucosamine and Dglucuronic acid. Alginate is a natural polymer composed of L-guluronic acid and D-Manuronic acid, the latter presenting a high homology with D-glucuronic acid of hyaluronan. Alginate has the ability to form hydrogels due to physical crosslinking with divalent metals. These hydrogels have low toxicity/inflammatory response and good biocompatibility; however, they are unstable over time [3]. Poly(2-hydroxyethyl methacrylate) (pHEMA) is a hydrophilic polymer highly studied in the formulation of biomaterials (among them, hydrogels); however, materials based on this polymer usually have a low capacity for cell adhesion and biocompatibility [9].

In this work, we have developed and studied semi-interpenetrated networks of 2-hydroxyethyl methacrylate (monomer) with different compositions of ethylene glycol dimethylacrylate (crosslinker) and azobisisobutyronitrile (initiator), containing alginate (natural polymer). The aim of this study was to evaluate if these changes in composition could produce biomaterials with different properties that, consequently, would affect cellular behavior. This would open the possibility to find a scaffold with the right characteristics to enhance tissue development and, therefore, to be applied in cartilage tissue engineering.

\section{Experimental}

\subsection{Materials}

Sodium alginate $\left(\mathrm{NaAlg}, \mathrm{M}_{\mathrm{W}}=120 \mathrm{Kg} / \mathrm{mol}\right)$ was purchased from Aldrich. It was purified before use according to Torres et al. [10] to eliminate impurities such as polyphenols and proteins. We have previously demonstrated that alginate purification improves bio- and cytocompatibility and osteoinduction, while decreasing toxicity. 2-hydroxyethyl methacrylate (HEMA, purified with column chromatography neutral alumina) and ethylene glycol dimethacrylate (EGDMA, purified with column chromatography neutral alumina) were obtained from Aldrich and Azobisisobutyronitrile (AIBN, recrystallized with methanol) was purchased from Sigma-Aldrich.

\subsection{Synthesis of Semi-interpenetrating polymer network (semi-IPN)}

Semi-interpenetrating hydrogels were synthesized employing various compositions of EGDMA or AIBN and the obtained membranes were denoted as SEMI 1, SEMI 2, SEMI 3 and SEMI 4. The variation in the amount of crosslinker (EGDMA) produces networks with different crosslinking density, so the properties (like mechanical, swelling) of the hydrogels obtained depend on the proportion of reagents used. Thus, more rigid hydrogels will be obtained by using a greater amount of crosslinker. In addition, the lesser quantities of initiator would imply a decrease in the amount of reactive species available to initiate polymerization, which would cause each reactive center to produce polymer chains of higher molecular weight; therefore the hydrogels synthesized under this condition will be less rigid. Furthermore, the influence of the different synthesis conditions of the hydrogels on the cellular response was analyzed. The sample designated as HEMA acted as control material which was prepared using distilled water instead of the alginate solution (Table 1). The 
selected reaction conditions and the experimental procedure carried out was based on bibliographic research [9-11]. In particular, $3.5 \mathrm{ml}$ of HEMA were added under stirring to the aqueous solution of sodium alginate $1 \% \mathrm{w} / \mathrm{v}(\mathrm{pH} 7-8)$ in a $1: 1$ volume ratio. EGDMA $(1 \%, 0.5 \%$ and $0.25 \% \mathrm{v} / \mathrm{v}$ with respect to HEMA + sodium alginate volume) and AIBN (1\% and $0.5 \% \mathrm{w} / \mathrm{v}$ with respect to HEMA + sodium alginate volume) were added later. After dissolution of AIBN, dissolved oxygen of the reaction mixtures was removed by purging with nitrogen gas for half an hour. Then, each mixture was poured between two glass plates spaced by a $1 \mathrm{~mm}$-thick Teflon cast to obtain uniform rectangular membranes. Reaction was performed at $60^{\circ} \mathrm{C}$ for $1 \mathrm{~h}$. Scheme 1 shows a representation of the semi-IPN hydrogels synthesized in this study.

[scheme 1 near here]

\section{[Table 1 near here]}

The obtained gel products were removed from the cast and washed for 2 days with boiling distilled water to remove residual unreacted monomers. Membranes were cut in its swollen state for their physicochemical and biological characterization and then sterilized by autoclaving for 15 minutes.

\subsection{Hydrogel characterization}

\subsubsection{Morphological characterization of hydrogels}

Hydrogel surfaces were coated with gold and their morphology was examined using SEM (Phillips 505, Holland), with an accelerating voltage of $20 \mathrm{kV}$. Images were analyzed by Soft Imaging System ADDAII. \% Porosity and surface pore size were measured using free Image $\mathbf{J}$ software.

Images for macroscopic observation were taken with a Nikon D3400 camera.

\subsubsection{Swelling and degradation studies.}

Swelling ( $\mathrm{Sw}$ ) of different hydrogels were evaluated during a 30-day incubation in Phosphate Buffered Saline (PBS, pH 7.4) and water. All experiments were carried out at $37^{\circ} \mathrm{C}$ in a humidified atmosphere containing 5\% $\mathrm{CO}_{2}$. Briefly, all hydrogels were cut, weighed $\left(\mathrm{W}_{0}\right)$ and then incubated in PBS or water for different periods of time. After each time-point, each sample was weighed $\left(\mathrm{W}_{\mathrm{t}}\right)$ and swelling percentage was evaluated by equation $1[12,13]$. After that, the samples were thoroughly washed with distilled water in order to remove the PBS salts, dried under vacuum and weighed $\left(\mathrm{W}_{\mathrm{dt}}\right)$ and the degradation percentage as weight loss (W) was evaluated by equation 2 .

$$
\begin{aligned}
& \% \mathrm{Sw}=\left(\mathrm{W}_{\mathrm{t}}-\mathrm{W}_{0}\right) \times 100 / \mathrm{W}_{0} \\
& \% \mathrm{~W}=\left(\mathrm{W}_{0}-\mathrm{W}_{\mathrm{dt}}\right) \times 100 / \mathrm{W}_{0}
\end{aligned}
$$

In order to determine the mechanism of diffusion of PBS and water into the hydrogels, we applied the following equation.

$$
\left(\mathrm{W}_{\mathrm{t}}-\mathrm{W}_{0}\right) / \mathrm{W}_{0}=\mathrm{Kt}^{\mathrm{n}}
$$

Where " $\mathrm{K}$ " is the swelling constant, " $\mathrm{t}$ " is time and " $\mathrm{n}$ " is a swelling exponential factor $[14,15]$. 
In addition, the cellular degradation of hydrogels was evaluated using RAW 264.7 macrophages. For this, $2.5 \times 10^{4}$ cells were seeded on each hydrogel and grown in Dulbecco's Modified Eagles minimal essential medium (DMEM) $+1 \%$ fetal bovine serum (FBS) at $37^{\circ} \mathrm{C}$ with $5 \% \mathrm{CO}_{2}$ in a humidified atmosphere. After 15 days, the hydrogels were thoroughly washed with $0.1 \%$ triton X100 in distilled water in order to remove any adhered cellular component. The percentage of weight loss was calculated using Equation 2.

\subsubsection{Contact angle.}

Water contact angle measurements of the hydrogels, dried or swollen for 2 days in PBS pH 7.4, were carried out as described previously $[16,17]$. All tests were performed on the air-facing surface of samples. For each sample, five measurements were performed on different points in order to calculate the mean static contact angle.

\subsubsection{Mechanical testing.}

Mechanical properties of polymeric scaffolds were determined with a universal testing machine (Digimess TC500) using a $50 \mathrm{~N}$ capacity force load cell (SM-50, Interface, Arizona, USA) at room temperature, in tensile mode. Briefly, after incubation of hydrogels for 2 days in PBS pH 7.4, they were cut in a rectangular form $(50 \mathrm{~mm} \times 18 \mathrm{~mm})$ and tested at a rate of $5 \mathrm{~mm} / \mathrm{min}$ until their breaking point. Elastic modulus (E) was calculated on the basis of the generated tensile stress-strain curves. The results presented are the mean values of eight independent measurements [18].

\subsection{Cell cultures and incubations.}

To perform all tests, the hydrogels were incubated with PBS for two days before cells were seeded.

Chondrocytic cells were used for bio- and cytocompatibility assays. Chondrocytes were isolated from the sternal xiphoid cartilage of Sprague-Dawley young rats after dissection of the perichondrium. Briefly, the cartilage was minced, washed three times in phosphate saline buffer $\mathrm{pH}$ 7.4 (PBS), and treated with trypsin for $15 \mathrm{~min}$ at $37^{\circ} \mathrm{C}$. The minced cartilage was washed an additional three times with PBS and incubated in DMEM-10\% FBS at $37^{\circ} \mathrm{C}, 95 \%$ air and $5 \% \mathrm{CO}_{2}$ in a culture flask, with half the culture media changed every 3 days [19]. All procedures were in accordance with the Guide for the Care and Use of Laboratory Animals published by the National Institutes of Health, and they were approved by the Institutional Laboratory Animal Care and Use Committee (CICUAL Protocol No. 019-00-15), Facultad de Ciencias Exactas, UNLP, Argentina.

Cells were grown in 6-well culture dishes for 2 or 10 days, after which chondrocytes were characterized by specific staining with alcian blue. Cells were rinsed with PBS, fixed with methanol at $-20^{\circ} \mathrm{C}$ for $30 \mathrm{~min}$, washed with distilled water and stained with alcian blue at $\mathrm{pH} 0.1$ overnight. After that time, cells were washed with distilled water and visualized by optical microscopy [13].

\subsubsection{Cell adhesion and proliferation.}

Cell adhesion and proliferation were evaluated by the 3-(4,5-dimethylthiazol-2-yl)-2,5-diphenyl tetrazolium bromide (MTT) assay. This assay measures reduction of the tetrazolium salt MTT to formazan by intact mitochondria in living cells. Thus, absorbance change is directly proportional to the number of viable cells. Briefly, $2.5 \times 10^{4}$ chondrocytes per well in basal media were plated onto the scaffolds which were casted in multi-well culture plates, and cultured $2 \mathrm{~h}$ for adhesion studies or 2 days for evaluation of proliferation. Cells were then incubated for two additional hours with a 
solution of $0.1 \mathrm{mg} \mathrm{mL}^{-1}$ MTT. After washing, the formazan precipitate was dissolved in dimethyl sulfoxide (DMSO) and absorbance read at $570 \mathrm{~nm}$.

\subsubsection{Reverse transcriptase (RT)-polymerase chain reaction $(P C R)$}

For RT-PCR studies, total ribonucleic acid (RNA) was isolated from cells grown on scaffolds for 10 days. TRIZOL reagent was used as indicated by the manufacturer (Invitrogen, Argentina). Expression of chondrocytic and osteogenic markers were performed by semi-quantitative RT-PCR using Moloney Murine Leukemia Virus Reverse Transcriptase (MMLV-RT) (Invitrogen, Argentina). Expressions of all markers were normalized to $\beta$-actin (housekeeping gene). Specific primers for all markers were designed from The National Center for Biotechnology Information (NCBI) sequence data using CLC Genomics Workbench software (QIAGEN) (Table 2) and synthesized by Macrogen (Seoul, Republic of Korea). After separation of RT-PCR products by agarose gel electrophoresis with GelRed, their corresponding band intensities were quantified using the gel plugin of MBF_ImageJ program.

\section{[Table 2 near here]}

\subsubsection{NO production by $R A W 264.7$ macrophages.}

Mouse macrophage RAW 264.7 cells were grown in DMEM supplemented with 5\% FBS and antibiotics $(100 \mathrm{U} / \mathrm{ml}$ penicillin and $100 \mathrm{ug} / \mathrm{ml}$ streptomycin) in a humidified atmosphere of $95 \%$ air and $5 \% \mathrm{CO}_{2}$. For the experiments, hydrogels were cut to size, inserted in each well of 24-well plates, and macrophages were plated on the films. Nitric oxide (NO) production was assessed using Griess reagent. The stable end-product of NO and nitrite released into the culture medium by RAW 264.7 cells was measured after 2 days of culture. Briefly, $500 \mu 1$ samples of conditioned media or nitrite standards $(0-100 \mathrm{nM})$ were mixed with $500 \mu \mathrm{l}$ of Griess reagent (1\% sulfanilamide and $0.1 \% \mathrm{~N}-(1$ Naphtyl)ethylenediamine in 5\% phosphoric acid) and absorbance was measured at $530 \mathrm{~nm}$ against a blank prepared with non-conditioned medium. RAW 264.7 cells were also plated on standard culture tissue dishes with lipopolysaccharide (LPS, $0.1 \mu \mathrm{g} / \mathrm{ml}$ ) as positive controls [10]. The results were normalized by counting the number of cells.

\subsection{Statistical analysis}

Results are expressed as mean \pm SD and, unless indicated otherwise, were obtained from two separate experiments performed in triplicate. Differences between groups were assessed by one-way ANOVA with Tuckey post hoc test using GraphPad InStat version 3.00 (GraphPad Software). p values less than 0.05 were considered significant for all statistical analyses.

\section{Results}

\subsection{Changes in surface topography with alginate incorporation}

Figure 1A shows SEM images of the surface morphology of hydrogels. HEMA hydrogels showed a smooth surface. On the contrary, the rest of hydrogels showed a porous surface when alginate was incorporated in the reaction mixture. Table 3 shows surface porosity and average pore size, indicating that both SEMI 1 and SEMI 4 have a higher percentage of porosity with a higher average pore size. 
Also, it can be seen from the macroscopic evaluation that HEMA (Figure 1B) presents a homogeneous and completely transparent surface; while SEMI 1, SEMI 2, SEMI 3 and SEMI 4 show a white and opaque appearance, without apparent heterogeneity.

[Figure 1A near here]

[Figure $1 B$ near here]

\subsection{Swelling behavior is modified in different hydrogels}

Figure 2A shows swelling in PBS after different time intervals. Table 3 shows the final swelling for each hydrogel after 30 days in PBS. This table shows that the inclusion of alginate in the reaction mixtures produced significant changes in swelling (only SEMI 4 swelled less than the material without alginate). The swelling capacity of hydrogels in increasing order is: SEMI $4<$ HEMA < SEMI 2 = SEMI $3<$ SEMI 1.

When observing results for swelling in water (Table 3), hydrogels can be ordered similarly in comparison to PBS. Interestingly, swelling of hydrogels in water was lower than their respective swelling in PBS.

\section{[Table 3 near here]}

In addition, after 5-7 hours in PBS, some of our hydrogels (HEMA, SEMI 1 and SEMI 2) showed a swelling behavior called "overshooting effect" (Figure 2B). In order to know the mechanism by which the swelling of our hydrogels occurred, the slope index $n$ was calculated after applying a logarithmic function to equation $3[14,15]$. Table 3 shows that for all cases, an $\mathrm{n}<0.5$ was obtained. Thus, the swelling of our hydrogels takes place by a mechanism called "Less Fickian".

\section{[Figure 2 near here]}

As can be seen in Figure 2A, maximum swelling for the hydrogels was achieved after 2 days of incubation in PBS. After this time, a balance was reached. That is why contact angle studies, mechanical testing and in vitro bio- and cytocompatibility tests were performed on the hydrogels prior to 2 days of swelling in PBS.

\subsection{The incorporation of alginate produces an increase in the degradation of hydrogels.}

In vivo, several mechanisms can be carried out in order to degrade the biomaterial, two of which are hydrolytic and mediated by macrophages. Degradation of the hydrogels was evaluated in water or in PBS (30 days, acellular hydrolytic mechanism), or with RAW 264.7 macrophages (15 days). In Figure 3, the percentage weight loss of hydrogels can be observed. It can be seen that when degradation is carried out in water, incorporation of alginate is associated with a significant increase in weight loss compared to HEMA alone. However, degradation in PBS (versus water) induced an increase in HEMA weight loss, but not for any of the other hydrogels. On the other hand, degradation by macrophage cells after 15 days was greater than the hydrolytic degradations due to both water and PBS after 30 days.

[Figure 3 near here] 


\subsection{The incorporation of Alginate changes the hydrophobicity of hydrogels.}

Table 3 shows the contact angle of different hydrogels, both dry and after 2 days in PBS. The introduction of alginate in all cases produced changes in the hydrophobicity of hydrogels.

Furthermore, large differences in WCA were found between the dry and swollen hydrogels of SEMI 2, SEMI 3 and SEMI 4, not so for HEMA and SEMI 1.

\subsection{Incorporation of alginate reduces stiffness of the hydrogels.}

The Young Modulus (E) for different hydrogels after 2 days in PBS are shown in Table 3. As can be seen, the Young Modulus calculated from the stress-strain curve for HEMA hydrogel, was $673 \mathrm{kPa}$. Incorporation of alginate into the different reaction mixtures produced hydrogels with a smaller Young Modulus, resulting in less rigid hydrogels than HEMA.

\subsection{Alginate content of the hydrogels modifies their in vitro bio- and cytocompatibility.}

Although chondrocytic cells have been previously characterized in our laboratory [19], we carried out a cell culture in order to demonstrate the reproducibility of their production through specific staining with Alcian blue. Figure 4 shows the cells grown during 2 and 10 days stained with alcian blue with a fibroblastic-like shape. Figure 4A shows a diffuse staining for the shorter culture periods, while in Figure 4B (10-day cultures) chondrogenic-like nodules can be observed.

Chondrocytic cells were grown on the hydrogels and their adhesion and proliferation was evaluated after $2 \mathrm{~h}$ and 2 days respectively. There were no significant differences in cell adhesion between hydrogels (Figure 4C). In addition, Figure 4D shows that chondrocyte cells proliferated better on SEMI 1 and SEMI $2(p<0.01)$ and SEMI 3 and SEMI $4(p<0.001)$ versus HEMA. Thus, the incorporation of sodium alginate to HEMA hydrogels increased cell proliferation.

\section{[Figure 4 near here]}

In order to evaluate the effect of alginate-containing hydrogels on the stability of the chondroctyte phenotype, in this study chondrocyte cells were grown for 10 days on the different scaffolds, as well as on plastic culture dishes (as control). After this culture period we determined cellular expression of the chondrocytic markers aggrecan, SOX 9 and type 2 collagen, as well as the non-chondrocytic marker type 1 collagen. Expression levels of aggrecan (Figure 5A), SOX9 (Figure 5B) and type 2 collagen (Figure 5C) were increased when chondrocytic cells were cultured on SEMI 1 to SEMI 4, versus both HEMA and control.

\section{[Figure 5 near here]}

Thus, the incorporation of alginate to the reaction mixture produces hydrogels that promote the expression of chondrogenic markers. However, stabilization of the chondrocytic phenotype must also be evaluated and so the expression of type 1 collagen was determined. Figure 5D shows similar levels of expression for this marker when chondrocytes were grown 10 days on HEMA, SEMI 1, SEMI 2 or plastic control, and a decrease in its expression when they were cultured on SEMI 3 or SEMI 4.

\subsection{Alginate-containing hydrogels decrease NO production.}


To evaluate the possible pro-inflammatory potential of the different hydrogels, RAW 264.7 macrophages on hydrogels or plastic control were cultured for 2 days and the NO release was determined. Figure 6 shows that NO production in all cases was lower than the positive control (LPS). Cells grown on HEMA produced slightly higher levels of NO compared to control. Interestingly, all alginate-containing hydrogels (SEMI 1 to SEMI 4) decreased macrophage NO production to control levels. Thus, the incorporation of alginate appears to prevent the slightly proinflammatory potential of HEMA.

\section{[Figure 6 near here]}

\section{Discussion:}

The cartilage can undergo different alterations due to inflammation, trauma or ageing, which can lead to chondrocyte depletion and degradation of the extracellular matrix [4]. As an alternative treatment, autologous chondrocyte transfer can be used [5] however, this has the disadvantage of phenotypic loss $[1,2,4]$. Different recent studies have attempted to synthesize scaffolds that can help transferred cells to regenerate cartilage while preserving their chondrocytic phenotype $[1,20]$. In our present work we have developed and characterized a series of semi-interpenetrating hydrogels (semiIPN) based on HEMA networks into which sodium alginate was added to improve their properties.

The need for a porous structure has proved to be a requirement for angiogenesis [21]. Loh et al. described that the minimum pore radius necessary for generating blood vessels is around $200 \mu \mathrm{m}$ [22]. However, although hydrogels were not obtained by techniques generally associated with the production of porous structures (solvent casting/particle leaching, freeze drying, electrospinning, gas foaming), the synthesis method used in our present study nevertheless produced hydrogels with nanopores (1000 times smaller than what is necessary for angiogenesis) and with a low percentage of porosity [23]. This could be beneficial, since Pelttari has demonstrated that cartilage hypertrophy after the ectopic transplants of mesenchymal cells was related to vascular invasion [24].

Cartilage is $75 \%$ water and because it is an avascular tissue, its viability depends on the diffusion of oxygen and nutrients through it [2]. Hydrogels are polymeric networks that have a great water retention capacity and their properties have attracted attention to be applied as scaffolds and drug delivery systems [25]. For this reason, we have studied the swelling capacity of the hydrogels obtained in this work. In the literature there are many studies that have evaluated the swelling capacity of hydrogels in water. However, since the objective of our materials is to be used in the regeneration of cartilage, we believe that it is more representative to perform swelling studies in PBS instead of water, because its osmolarity (isotonic) and ion concentration $\left(\mathrm{PO}_{4}^{-2}, \mathrm{Cl}^{-}, \mathrm{Na}^{+}\right.$and $\left.\mathrm{K}^{+}\right)$is very similar to that of the extracellular fluid of different mammals. In this way we demonstrate that, in order to perform better extrapolations of in vitro results to in vivo predictions, it is not enough to know the swelling of biomaterials in water. Studies should be carried out in conditions that resemble the physiological situation as closely as possible.

During 5-7 hours of swelling in PBS, the hydrogels HEMA, SEMI 1 and SEMI 2 had been a swelling behavior called "overshooting effect". This effect results in maximum swelling with subsequent reduction until a new equilibrium is reached. The cause of this effect is not yet fully understood and may be due to a combination of factors such as solvent polarity, solvent ionic strength, solvent diffusion rate, chain relaxation rate and ion-covalent crosslinking [21]. In addition, in table 3, it can be observed an increase in liquid uptake by SEMI 1 compared to HEMA $(\mathrm{p}<0.01)$ membranes, for the swelling study in PBS, introducing a hydrophilic polymer such as alginate to a polymer network enhances its liquid absorption properties. This polysaccharide causes repulsive electrostatic forces in the network due to the negative charges of the carboxylate functional groups, which causes a widening of the space between the polymeric chains that favors swelling. The 
variation in the content of crosslinker as the decrease in the amount of initiator in the preparation of the membranes does not seem to have a relevant effect on the swelling behavior, as if observed when incorporating the polysaccharide to the samples.

On the other hand, the parameter $\mathrm{n}$ has been evaluated in order to know the swelling mechanism, noting that for all hydrogels, the mechanism turns out to be called "Less Fickian". In this swelling process the penetration rate of the solvent into the hydrogel is much lower than the relaxation rate of the polymer chains [14]. Although one could assume that this behavior is due to the ionic strength of the solvent (PBS), in swelling studies with water we also obtained an $n<0.5$ (Table 3 ). In the literature there are few cases that report hydrogels with an $n<0.5$; coincidentally, one of these studies [26] evaluated polymers synthesized with HEMA. These authors synthesized several hydrogels using HEMA and styrene, for which they observed a "Less Fickian" behavior when studying their swelling in water. In addition, they synthesized a hydrogel using only HEMA which, despite differences in the synthetic processes, had a \% swelling similar to our present results.

Once the hydrogels are implanted at the site to be repaired, it is important that they are degraded as new tissue is produced [27]. In vivo, several mechanisms can be carried out in order to degrade the biomaterial, two of which are hydrolytic and/or mediated by macrophages. In those studies, we observed a low percentage of weight loss when degraded in PBS after 30 days, but this percentage increased significantly after 15 days of degradation with RAW 264.7 macrophages. These results are in agreement with other previous studies, where we evaluated the degradation of two hydrogels synthesized with polycaprolactone or poly (L-lactide) and containing poly (2-hydroxyethyl acrylate) [18]. Similarly, Mabilleau et al. studied the degradation of pHEMA-EGDMA by J774.2 macrophage cells. They observed that the cells produced the degradation of the material through superficial erosion [28]. In the present study, we have found that the incorporation of alginate induces a significant increase in macrophage degradation (for all alginate-containing hydrogels versus HEMA).

Despite these results, performing an extrapolation from in vitro to in vivo degradation behavior would not be adequate. In vivo systems involve dynamic and complex physiological processes that are not accurately represented by in vitro models.

Water contact angle (WCA) is an indicator of wettability of a material's surface and this term could be defined as the ease with which a fluid can adhere to and/or propagate through a solid surface [29]. Since the initial interactions between cells and the surface of the material are relatively weak, water angle contact is an important parameter to evaluate [16]. In our study, for dry hydrogels, only when alginate was incorporated without changing the proportions of EGDMA and AIBN, were more hydrophilic hydrogels obtained than without alginate (SEMI 1 vs. HEMA). All other dry hydrogels were less hydrophilic than HEMA. However, when we performed these studies after two days of swelling in PBS, the only hydrogel that was less hydrophilic than HEMA, was when a concentration of $0.5 \%$ of EGDMA was used (SEMI 2). The rest of the PBS-swollen hydrogels were more hydrophilic than PBS-swollen HEMA. These variations in WCA could be due to changes in the chemical composition of the different hydrogels. However, our group has previously shown that changes in the topography of scaffolds that are chemically equal can also induce changes in WCA $[16,30]$. Therefore, the hydrophobicity/hydrophilicity of a scaffold results not only from the compromise between the chemical composition and topography of its constituents, but also from the degree of swelling of the material and, probably, the type of solvent that has been used to swell.

It is of great importance to be able to evaluate biomaterials from a mechanical point of view in order to know if, once implanted, they will collapse or maintain their shape to ensure tissue regeneration. Lu et al. reports that the Young Modulus for native cartilage is between 320 and 1020 $\mathrm{kPa}$; thus, only two of our novel hydrogels (SEMI 2 and SEMI 3) have a smaller module than that 
reported for cartilage [31]. In addition, when analyzing the results obtained (see Table 3), it was observed that the incorporation of alginate to all the membranes produces more flexible materials (lower Young Modulus). A similar effect was observed by La Gatta and co-workers, who showed that the incorporation of alginate into a hydrogel obtained by pHEMA-METAC, produced a decrease in Young Modulus in an alginate concentration-dependent way [9].Particularly as the concentration of the crosllinking agent lessens (from SEMI 1 to SEMI 3), the value of the Young's modulus decreases due to the reduction in the crosslinking density of the matrix, thus generating less rigid materials as expected.

In addition to the physicochemical characterizations, it is necessary to carry out biocompatibility studies of the materials in order to evaluate their possible behavior once implanted in the body. In this work, chondrogenic primary cells are used in order to assess the ability of biomaterials to maintain not only cell viability, but also its phenotype. When performing the routine characterization of the cell culture, we found formation of nodules with deposition of extracellular matrix with Alcian blue stain positive, being in agreement with other authors [32-34]. One of the main disadvantages of the use of chondrocytes from autologous sources is that during the expansion of the culture in monolayers, these cells de-differentiate losing their ability to express chondrocytic phenotypic markers $[4,35]$ and their morphology changes resembling a fibroblastic cell $[1,36]$. As the number of culture passages of these cells increases, not only do the expression levels of genes such as type 2 collagen, GAGs, aggrecan and SOX9 decrease, but cells also increase the expression of non-chondrongenic genes such as type 1 collagen. Other authors have shown that the spatial organization in the culture is essential for a correct production of extracellular matrix by chondrocytes [31]. Therefore, the incorporation of alginate into the reaction mixture produces hydrogels that, when used as a scaffold to grow cartilage-derived cells, can increase the expression of chondrogenic markers (SEMI 1 to SEMI 4) and can additionally favor the stability of the chondrocytic phenotype (SEMI 3 and SEMI 4). This can be partly due to the generation of a more hydrophilic and porous environment. In addition, alginate has some similarity to hyaluronic acid, which is a component of cartilage extracellular matrix and has been shown to have a fundamental role in the proliferation and differentiation of chondrocytes [8].

An important requirement for all biomaterials is that they must be non-toxic and noninflammatory. RAW 264.7 is a cell line derived from Mus musculus (mouse) macrophages that expresses different inflammatory markers (NO production, expression of NO synthases and Interleukins) when it is exposed to toxic and/or immunogenic substances. Thus, these cells are an excellent in vitro model to determine whether a new biomaterial is potentially inflammatory [37, 38]. Wang et al have developed an interesting series of thermogels which have the ability to induce a controllable inflammatory capacity once implanted subcutaneously [39].

In our system, RAW 264.7 cells grown on HEMA, have produced an increase (slight but significant) in the NO synthesis compared to the control, however, this toxic effect was prevented by incorporating alginate. Other authors have synthesized an alginate-containing HEMA-co-METACbased hydrogel [9]. Although they used another cell type for pro-inflammatory evaluation, they also demonstrated an absence of negative effects when the HEMA network was semi-interpenetrated with alginate. Recently, Kim et al. have also developed a hydrogel using HEMA and alginate [40]. Using human bone marrow mesenchymal cells, they proved their biomaterial to be cytocompatible. However, since their hydrogel was not swellable it could not be recommended for cartilage regeneration. Without the ability to swell or heat sensitive, the diffusion of nutrients, cells and blood vessels will be limited, delaying the repair of cartilage [41].

\section{Conclusion:}


In conclusion, the incorporation of alginate into a network of HEMA-EGDMA has given us a semi-interpenetrated material (SEMI) with improved swelling capacity, long-term stabilization of chondrogenic phenotype, and reduced pro-inflammatory potential. At the same time, we have demonstrated that these properties are not only improved by the incorporation of alginate, but also by varying the concentrations of initiator and crosslinker in order to obtain a family of semiinterpenetrated networks with versatile properties. In a nutshell, we have developed a series of hydrogels with promising potential for cartilage regeneration.

\section{Acknowledgments:}

This work was partially supported by grants from Facultad de Ciencias Exactas, Universidad Nacional de La Plata (UNLP), Comisión de Investigaciones Científicas de la Provincia de Buenos Aires (CICPBA) and Agencia Nacional de Promoción Científica y Tecnológica (PICT 2015-1030). MLT is a fellow of CONICET, TGO and JMF are a member of the Carrera del Investigador of CONICET.

\section{References:}

1. Armiento AR, Stoddart MJ, Alini M, et al. Biomaterials for articular cartilage tissue engineering: Learning from biology. Acta Biomater. 2018;65:1-20.

2. Correa D, Lietman S. Articular cartilage repair: Current needs, methods and research directions. Semin. Cell Dev. Biol. 2017;62:67-77.

3. Yang J, Zhang YS, Yue K, et al. Cell-laden hydrogels for osteochondral and cartilage tissue engineering. Acta Biomater. 2017;57:1-25.

4. Vinatier C, Guicheux J. Cartilage tissue engineering: From biomaterials and stem cells osteoarthritis treatments. Ann. Phys. Rehabil. Med. 2016;59:139-144.

5. Liu Y, Zhou W, Cao Y. Recent progress in cartilage tissue engineering-our experience and future directions. Engineer. 2017;3:28-35.

6. Wang C, Feng N, Chang F, Wang J, Yuan B, Cheng Y, Liu H, Yu J, Zou J, Ding J, Chen X. Injectable Cholesterol Enhanced Stereocomplex Polylactide Thermogel Loading Chondrocytes for Optimized Cartilage Regeneration. Advanced healthcare materials. 2019;8(14):1900312.

7. Langer R and Vacanti JP. Tissue engineering. Sci. 1993;14:920-926.

8. Li L, Yu F, Zheng L, et al. Natural hydrogels for cartilage regeneration: Modification, preparation and application. J. Orthop. Trans. 2019;17:26-41. 
9. La Gatta A, Schiraldi C, Esposito A, et al. Novel poly(HEMA-co-METAC)/alginate semiinterpenetrating hydrogels for biomedical applications: Synthesis and characterization. J. Biomed. Mater. Res. 2000;90A:292-302.

10. Torres ML, Fernandez JM, Dellatorre FG, et al. Purification of alginate improves its biocompatibility and eliminates cytotoxicity in matrix for bone tissue engineering. Algal Res. 2019;40:101499.

11. Babu S, Kim C, Kim S, et al. Development of semi-interpenetrating carbohydrate polymeric hydrogels embedded silver nanoparticles and its facile studies on E. coli. Carbohydr Polym. 2010;81:196-202.

12. Olad A, Pourkhiyabi P, Gharekhani H, et al. Semi-IPN superabsorbent nanocomposite based on sodium alginate and montmorillonite: Reaction parameters and swelling characteristics. Carbohydr Polym. 2018;190:295-306.

13. Fernandez JM, Oberti TG, Vikingsson L, et al. Biodegradable polyester networks including hydrophilic groups favor BMSCs differentiation and can be eroded by macrophage action. Polym Degrad Stabil. 2016;130:38-46.

14. Ganji F, Vasheghani-Farahani S, Vasheghani-Farahani E. Theoretical Description of Hydrogel Swelling: A Review. Iran Polym. J. 2010;19:375-398.

15. Karadag E, Saraydin D. Swelling studies of super water retainer acrylamide/crotonic acid hydrogels crosslinked by trimethylolpropane triacrylate and 1,4-butanediol dimethacrylate. Polym Bull. 2002;48:299-307.

16. Alfano AL, Fernandez JM. Induction of topographical changes in PCL scaffolds for bone tissue engineering: biocompatibility and cytotoxicity evaluations. J Biomater Tiss Eng. 2015;5:142-149.

17. Fernandez JM, Cortizo MS, Cortizo AM, et al. Osteoblast Behavior on Novel Porous Polymeric Scaffolds. J Biomater Tiss Eng. 2011;1:86-92. 
18. Fernandez JM, Molinuevo MS, Cortizo AM, et al. Characterization of Poly $(\varepsilon-$ caprolactone)/Polyfumarate Blends as Scaffolds for Bone Tissue Engineering. Biomater Sci Polymer. 2010;21:1297-1312.

19. Lastra ML, Molinuevo MS, Cortizo AM, et al. Fumarate copolymer-Chitosan cross-linked scaffold directed to osteochondrogenic tissue engineering. Macromol. Biosci. 2016;17:1600219-1600230.

20. Ansari S, Khorshidi S, Karkhaneh A. Engineering of gradient osteochondral tissue: From nature to lab. Acta Biomater. 2019;87:41-54.

21. Annabi N, Zhong JW, Ji X, et al. Controlling the porosity and microarchitecture of hydrogels for tissue engineering. Tissue Eng: Part B. 2010;16:371-383.

22. Loh QL, Choong C. Three-dimensional scaffolds for tissue engineering applications: role of porosity and pore size. Tissue Eng. Part B. 2013;19:485-502.

23. Sornkamnerd S, Okajima MK, Kaneko T. Tough and porous hydrogels prepared by simple lyophilization of LC Gels. ACS Omega. 2017;2:5304-5314.

24. Pelttari K, Winter A, Steck E, et al. Premature Induction of hypertrophy during in vitro Chondrogenesis of Human Mesenchymal Stem Cells correlates with calcification and vascular invasion after ectopic transplantation in SCID mice. Arthritis Rheumatol. 2006;54:3254-3266.

25. Qiu H, Guo H, Li D, et al. Intravesical hidrogels as drug Reservoirs. Trends in Biotechnology. 2018;38:579-583.

26. Wang J, Wu W, Li Z. Kinetics and Thermodynamics of the Water Sorption of 2Hydroxyethyl Methacrylate/Styrene Copolymer Hydrogels. J Appl Polym Sci. 2008;109:3018-3023.

27. Li S, Dong S, Xu W, et al. Antibacterials Hydrogels. Advanced Science. 2018;5:1700527. 
28. Mabilleau G, Moreau MF, Filmon R, et al. Biodegradability of poly (2-hydroxyethyl methacrylate) in the presence of the J774. 2 macrophage cell line. Biomaterials. 2004;25:5155-5162.

29. Menzies KL, Jones L. The impact of contact angle on the biocompatibility of biomaterials. Optom Vis Sci. 2010;87:387-399.

30. Cortizo AM, Ruderman G, Correa G, et al. Effect of Surface Topography of Collagen Scaffolds on Cytotoxicity and Osteoblast Differentiation. J Biomater Tiss Eng. 2012;2:125132.

31. Lu L, Zhu X, Valenzuela RG, et al. Biodegradable polymer scaffolds for cartilage tissue engineering. Clin. Orthop. Relat. Res. 2001;391s:s251-s270.

32. De Bari C, Dell'Accio F, Luyten PP. Human periosteum-derived cells maintain phenotypic stability and chondrogenic potential throughout expansion regardless of donor age. Arthritis Rheum. 2001;44:85-95.

33. Lin SS, Tzeng BH, Lee KR, et al. $\mathrm{Ca}_{\mathrm{v}} 3.2$ T-type calcium channel is required for the NFATdependent Sox9 expression in tracheal cartilage. Proc. Natl. Acad. Sci. U.S.A. 2014;111:E1990-E1998.

34. Voga M, Drnovsek N, Novak S, et al. Silk fibroin induces chondrogenic differentiation of canine adipose-derived multipotent mesenchymal stromal cells/mesenchymal stem cells. J Tissue Eng. 2019;10:1-14.

35. Dubey NK, Deng WP. Polymeric Gels: Characterization, Properties and Biomedical Appliactions; 2018.Chapter 20, Polymeric gels for cartilage tissue engineering.

36. Krajewska-Włodarczyk M, Owczarczyk-Saczonek A, Placek W, et al. Articular Cartilage aging-potential regenerative capacities of cell manipulation and stem cell therapy. Int $\mathrm{J}$ Mol Sci. 2018;19:623-648.

37. Lastra ML, Ribelles JL, Cortizo AM. Design and characterization of microspheres for a 3D mesenchymal stem cell culture. Colloids and Surfaces B: Biointerfaces. 2020;196:111322. 
38. Costantino ML, Cortizo MS, Cortizo AM, Oberti TG. Osteogenic scaffolds based on fumaric/N-isopropylacrylamide copolymers: Designed, properties and biocompatibility studies. European Polymer Journal. 2020;122:109348.

39. Wang Y, Jiang Z, Xu W, Yang Y, Zhuang X, Ding J, Chen X. Chiral polypeptide thermogels induce controlled inflammatory response as potential immunoadjuvants. ACS Appl Mater Interface. 2019;11:8725-30.

40. Kim YW, Kim JE, Jung Y, et al. Non-swellable, cytocompatible HEMA-alginate hydrogels with high stiffness and toughness. Mater Sci Eng C. 2019;95:86-94.

41. Zhang Y, Yu J, Ren K, Zuo J, Ding J, Chen X. Thermosensitive hydrogels as scaffolds for cartilage tissue engineering. Biomacromolecules. 2019;20(4):1478-92. 
Table 1: Composition in reaction mix of different hydrogels

\begin{tabular}{|c|c|c|c|c|}
\hline Name & $\begin{array}{c}\text { HEMA/H2O } \\
\text { relation }\end{array}$ & $\begin{array}{c}\text { HEMA/Sodium } \\
\text { Alginate relation }\end{array}$ & EGDMA & AIBN \\
\hline HEMA & $1: 1$ & - & $1 \%$ & $1 \%$ \\
\hline SEMI 1 & - & $1: 1$ & $1 \%$ & $1 \%$ \\
\hline SEMI 2 & - & $1: 1$ & $0.5 \%$ & $1 \%$ \\
\hline SEMI 3 & - & $1: 1$ & $0.25 \%$ & $1 \%$ \\
\hline SEMI 4 & - & $1: 1$ & $1 \%$ & $0.5 \%$ \\
\hline
\end{tabular}


Table 2: Primer sequences (forward and reverse) for chondrogenic and osteogenic markers.

\begin{tabular}{|c|c|c|c|c|}
\hline $\begin{array}{c}\text { Marke } \\
\mathbf{r}\end{array}$ & $\begin{array}{l}\text { Genbank } \\
\text { code }\end{array}$ & $\begin{array}{l}\text { Product size } \\
\text { (bp) }\end{array}$ & & Sequence \\
\hline \multirow{2}{*}{$\beta$-actin } & \multirow{2}{*}{$\begin{array}{c}\text { NM_031144. } \\
3\end{array}$} & \multirow{2}{*}{345} & $\begin{array}{l}\mathrm{F} \\
\mathrm{W}\end{array}$ & CCTTCAACACCCCAGCCAT \\
\hline & & & $\begin{array}{l}\mathrm{R} \\
\mathrm{V}\end{array}$ & CATAGCTCTTCTCCAGGGA \\
\hline \multirow{2}{*}{$\begin{array}{l}\text { Aggrec } \\
\text { an }\end{array}$} & \multirow{2}{*}{$\begin{array}{c}\text { NM_0221190 } \\
.1\end{array}$} & \multirow{2}{*}{525} & $\begin{array}{l}\mathrm{F} \\
\mathrm{W}\end{array}$ & CCATCCCCTGCTACTTCATC \\
\hline & & & $\begin{array}{l}\mathrm{R} \\
\mathrm{V}\end{array}$ & CACCATAGCAACCTTCCC \\
\hline \multirow{2}{*}{ SOX 9} & \multirow{2}{*}{$\begin{array}{c}\text { NM_080403. } \\
1\end{array}$} & \multirow{2}{*}{503} & $\begin{array}{l}\mathrm{F} \\
\mathrm{W}\end{array}$ & TCTCTTGGACCCCTTCAT \\
\hline & & & $\begin{array}{l}\mathrm{R} \\
\mathrm{V}\end{array}$ & GGTGGTCTTTCTTGTGCT \\
\hline \multirow{2}{*}{ Col t1 } & \multirow{4}{*}{ NM_053304. } & \multirow{2}{*}{651} & $\begin{array}{l}\mathrm{F} \\
\mathrm{W}\end{array}$ & GCATACACAATGGCCTAA \\
\hline & & & $\begin{array}{l}\mathrm{R} \\
\mathrm{V}\end{array}$ & CTGTTCCAGGCAATCCAC \\
\hline \multirow{2}{*}{ Col t2 } & & \multirow{2}{*}{295} & $\begin{array}{l}\mathrm{F} \\
\mathrm{W}\end{array}$ & GGGGCAGAAAGGAGAACCT \\
\hline & & & $\begin{array}{l}\mathrm{R} \\
\mathrm{V}\end{array}$ & TTGCATGACTCCCATCTGG \\
\hline
\end{tabular}


Table 3: \% of porosity, pore size, contact angle before and after 2 days in PBS and Elastic modulus (E) of different hydrogels. $n$ and $\%$ swelling (\% Sw) in PBS and water. $a: p<0.01$ vs. HEMA; $b$ : $p<0.01$ vs. SEMI 1; c: $p<0.01$ vs. SEMI 2; $d: p<0.01$ vs. SEMI 3.

\begin{tabular}{|c|c|c|c|c|c|}
\hline Name & $\begin{array}{l}\text { Porosity } \\
\qquad \%)\end{array}$ & $\begin{array}{c}\text { Pore size } \\
\text { (nm) }\end{array}$ & $\begin{array}{c}\text { Dry } \\
\text { Contact } \\
\text { angle } \\
\left(^{\circ}\right)\end{array}$ & $\begin{array}{c}\text { Swollen } \\
\text { Contact } \\
\text { angle } \\
\left(^{\circ}\right)\end{array}$ & $\begin{array}{c}\mathbf{E} \\
(\mathbf{k P a})\end{array}$ \\
\hline HEMA & ND & ND & $52.1 \pm 0.7$ & 51.70 .7 & $673 \pm 44$ \\
\hline SEMI 1 & $\begin{array}{c}12.00 \pm 0.0 \\
7\end{array}$ & $312.7 \pm 6.9$ & $\begin{array}{c}48.9 \pm 0.4 \\
a\end{array}$ & $\begin{array}{c}49.1 \pm 0.8 \\
\mathrm{a} \\
\end{array}$ & $516 \pm 30 a$ \\
\hline SEMI 2 & $\begin{array}{c}1.98 \pm 0.03 \\
b\end{array}$ & $\begin{array}{c}199.6 \pm 7.1 \\
\text { B }\end{array}$ & $\begin{array}{c}62.1 \pm .1 \\
a, b\end{array}$ & $\begin{array}{c}52.3 \pm 0.7 \\
\text { a,b }\end{array}$ & $\begin{array}{c}204 \pm 8 \\
a, b\end{array}$ \\
\hline SEMI 3 & $\begin{array}{c}0.56 \pm 0.07 \\
b, c\end{array}$ & $\begin{array}{c}129.4 \pm 10.3 \\
\text { b,c }\end{array}$ & $\begin{array}{c}64.7 \pm 0.3 \\
a, b, c\end{array}$ & $\begin{array}{c}41.7 \pm 0.4 \\
a, b, c\end{array}$ & \\
\hline SEMI 4 & $\begin{array}{c}13.83 \pm 0.1 \\
9 \mathrm{c}, \mathrm{d}\end{array}$ & $\begin{array}{c}310.2 \pm 9.1 \\
\mathrm{c}, \mathrm{d}\end{array}$ & $\begin{array}{c}63.6 \pm 0.2 \\
a, b\end{array}$ & $\begin{array}{c}45.5 \pm 0.8 \\
\mathrm{a}, \mathrm{b}, \mathrm{c}, \mathrm{d}\end{array}$ & $\begin{array}{l}374 \pm 27 \\
a, b, c, d\end{array}$ \\
\hline & \multicolumn{2}{|r|}{ In PBS } & \multicolumn{3}{|c|}{ In Water } \\
\hline & $\mathbf{n}$ & $\%$ Sw (at 30 days) & $\mathbf{N}$ & \multicolumn{2}{|c|}{$\%$ Sw (at 30 days) } \\
\hline HEMA & 0.38 & $74.8 \pm 0.5$ & 0.33 & \multicolumn{2}{|c|}{$61.3 \pm 1.6$} \\
\hline SEMI 1 & 0.33 & $86.6 \pm 1.1 \mathrm{a}$ & 0.32 & \multicolumn{2}{|c|}{$69.2 \pm 0.8 \mathrm{a}$} \\
\hline SEMI 2 & 0.38 & $79.2 \pm 1.0 \mathrm{a}, \mathrm{b}$ & 0.36 & \multicolumn{2}{|c|}{$69.2 \pm 2.9 \mathrm{a}$} \\
\hline SEMI 3 & 0.34 & $81.7 \pm 0.9 \mathrm{a}, \mathrm{b}$ & 0.37 & \multicolumn{2}{|c|}{$67.4 \pm 1.0$} \\
\hline SEMI 4 & 0.29 & $68.7 \pm 0.5 \mathrm{a}, \mathrm{b}, \mathrm{c}, \mathrm{d}$ & 0.38 & \multicolumn{2}{|c|}{$57.8 \pm 0.4 \mathrm{~b}, \mathrm{c}, \mathrm{d}$} \\
\hline
\end{tabular}


Figure 1 A

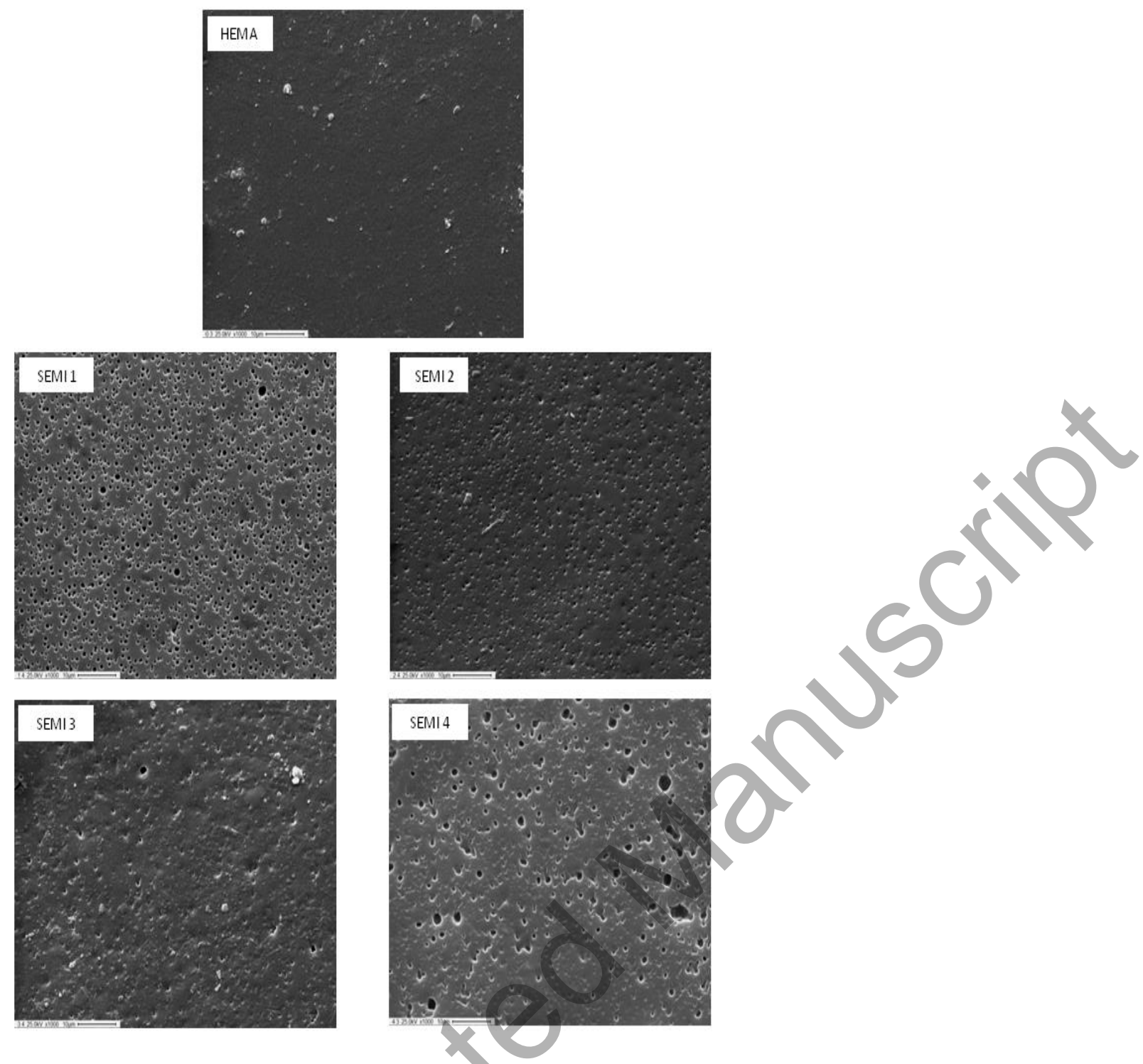

Figure 1 B

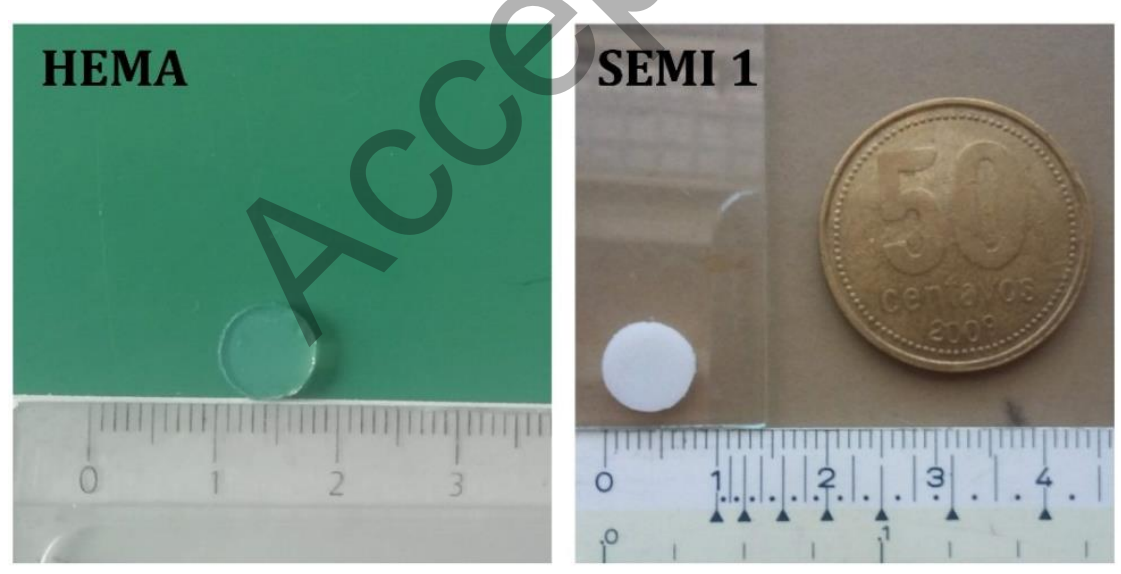

Fig. 1: SEM image of hydrogels at a magnification of 1000. The scale bars correspond to $10 \mu \mathrm{m}(\mathrm{A})$. Images of scaffolds for macroscopic evaluation (B) of HEMA and SEMI 1, also representative of SEMI 2, SEMI 3 and SEMI 4. 


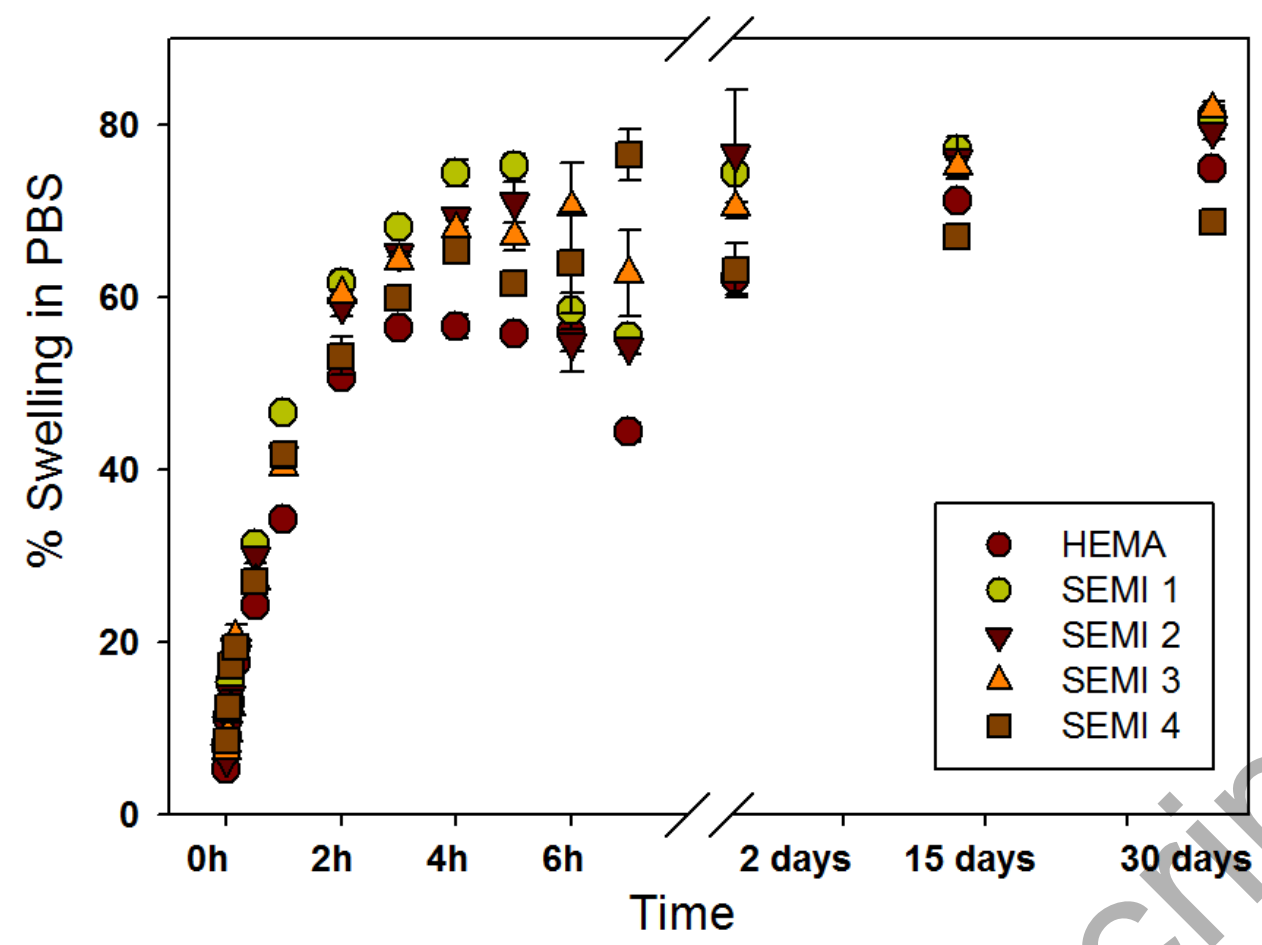

Figure 2 B

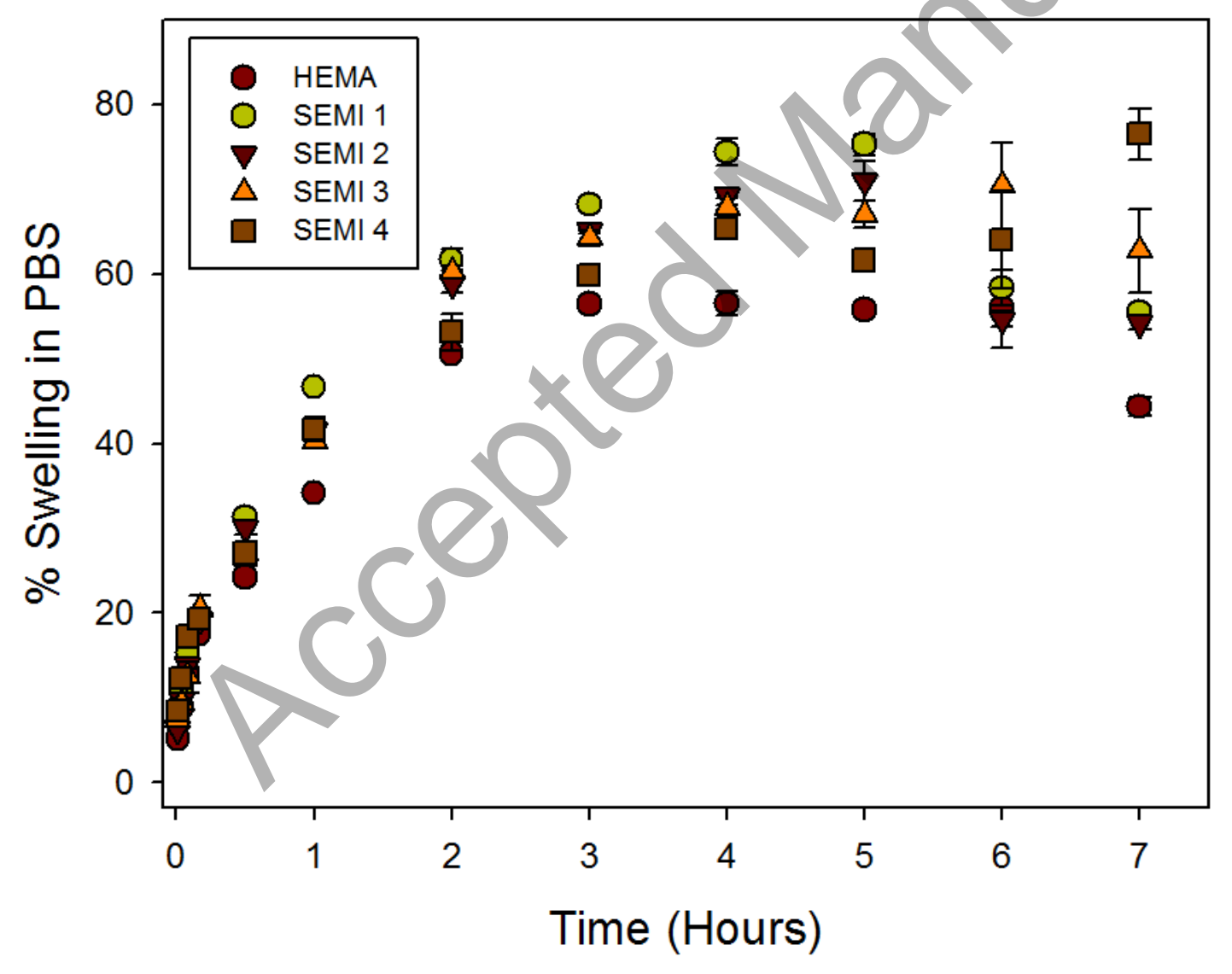

Fig. 2: Swelling of hydrogels in PBS during 30 days (A) and during 7 hours (B). 


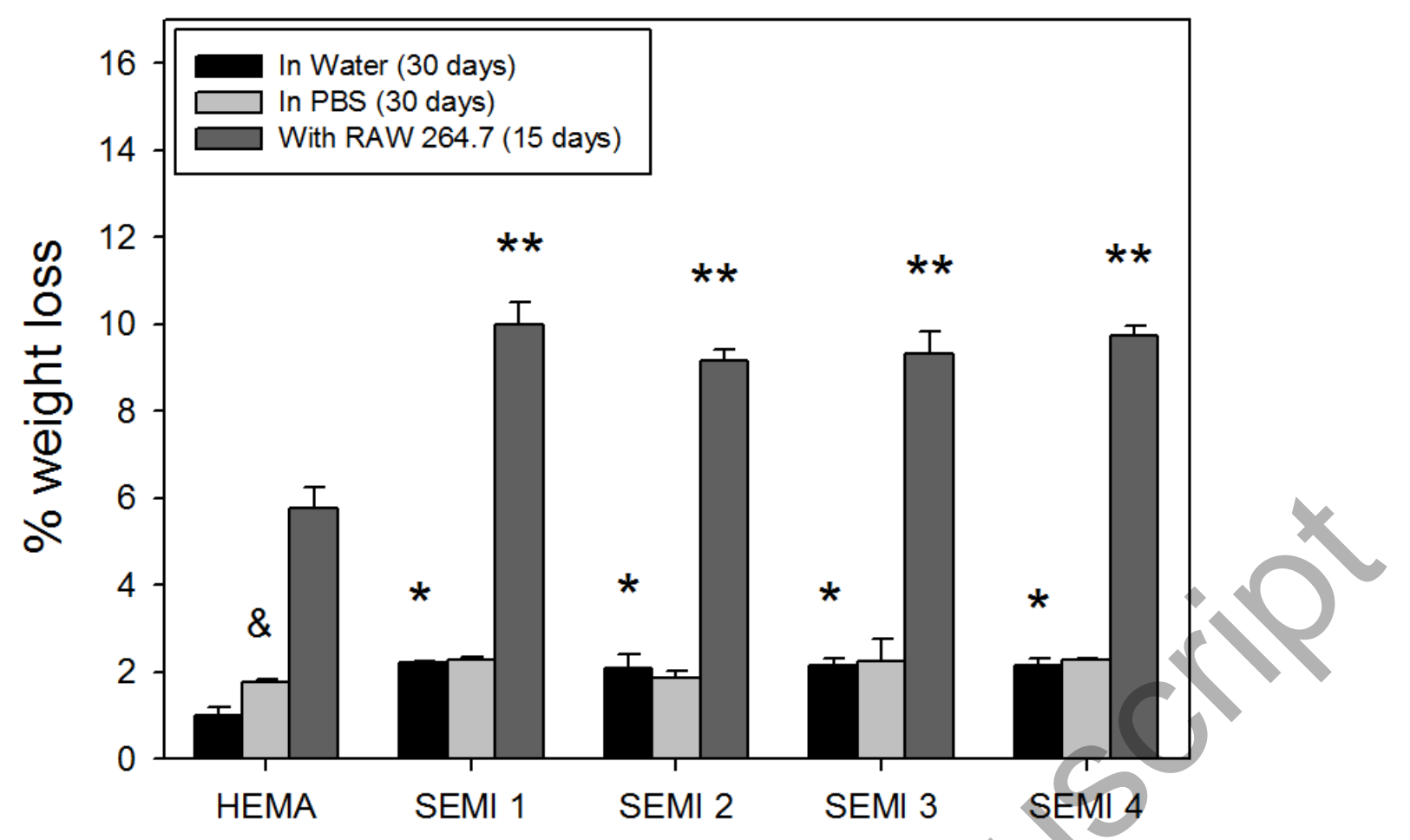

Fig. 3: \% weight loss of the hydrogels after degradation in water and PBS for 30 days and by RAW 264.7 cells after 15 days. $\&$ : $p<0.05$ respect to HEMA in water. $* *: p<0.01$ respect to HEMA with RAW 264.7. 

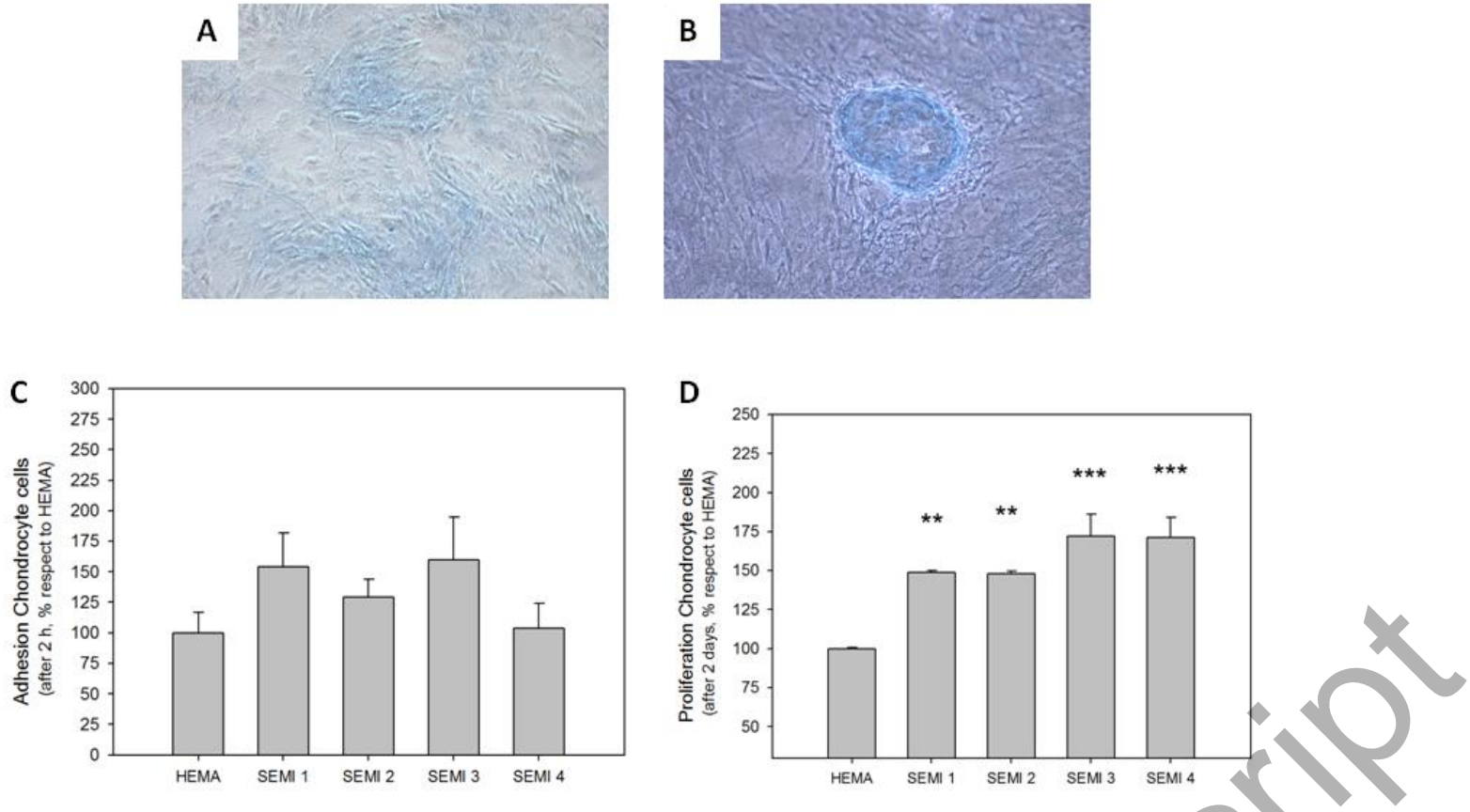

Fig. 4: Chondrocytes cells grown over culture dish after 2 (A) and 10 (B) days stained with alcian blue. Magnification 400X. C) Adhesion of Chondrocytes cells after $2 \mathrm{~h}$ over hydrogels D) Chondrocytes cells proliferation after 2 days over the hydrogels. ${ }^{* *}: \mathrm{p}<0.01$ vs. HEMA; $* * *: p<0.001$ vs. HEMA. 
A
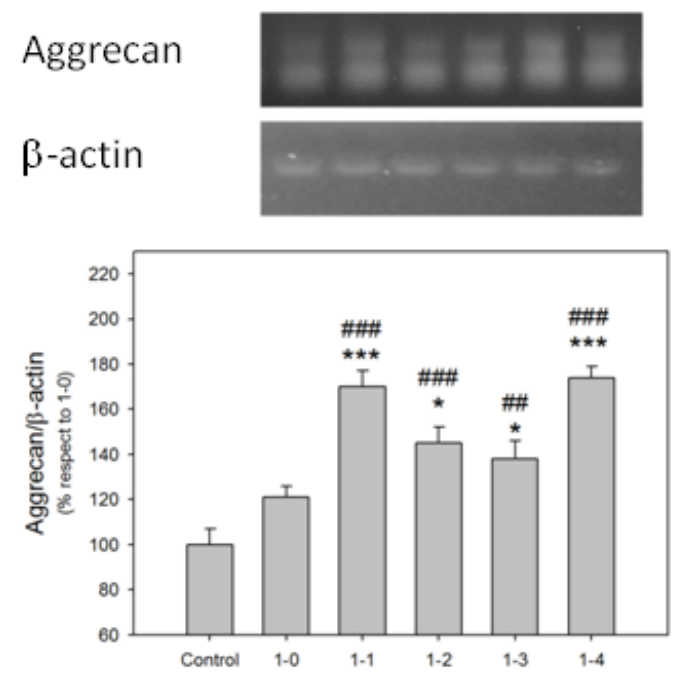

\section{B}
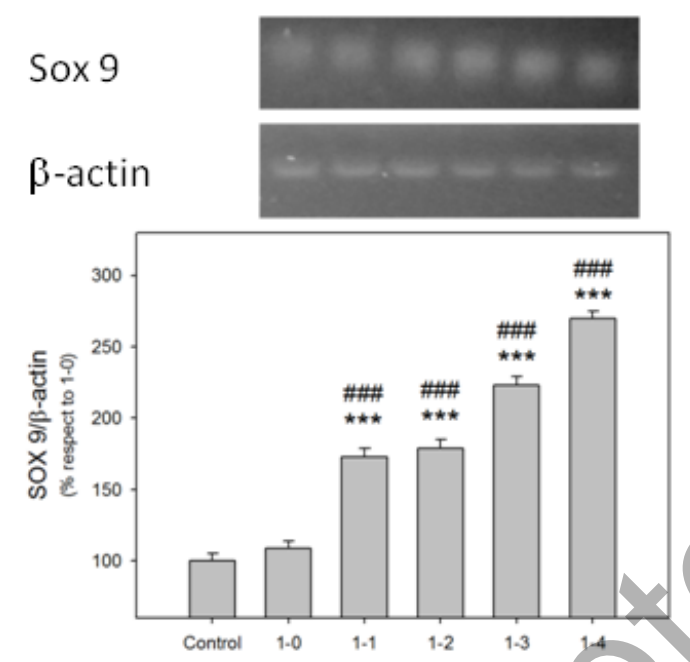

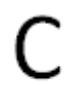

t2 collagen

$\beta$-actin
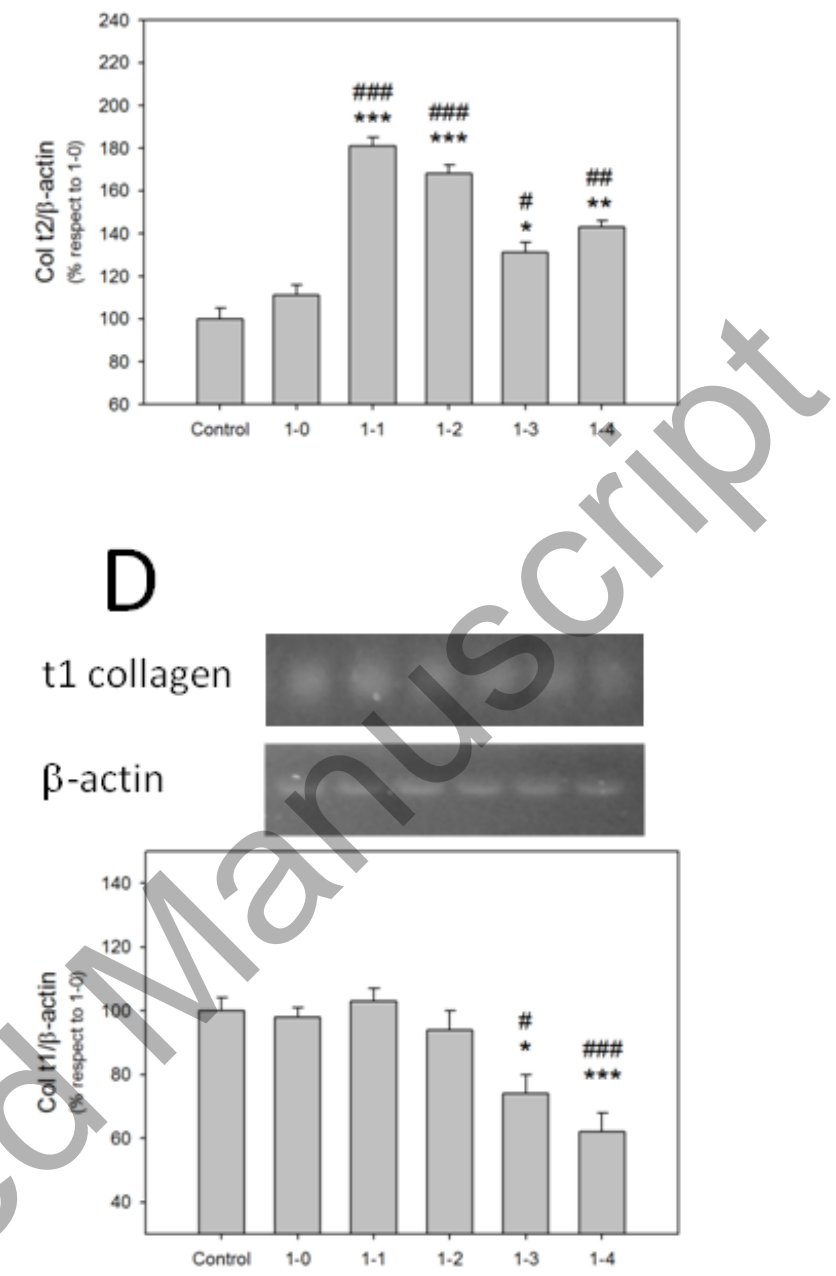

Fig. 5: Chondrogenic marker (A, B and C) and Osteoblastic marker (D) expressions of Chondrocytes cells grown over the hydrogels during 10 days. \#: $\mathrm{p}<0.05$ vs. Control; \#\#: $\mathrm{p}<0.01$ vs. Control; \#\#\#: p<0.001 vs. Control; *: $\mathrm{p}<0.05$ vs. HEMA; **: $\mathrm{p}<0.01$ vs. HEMA; ***:p<0.001 vs. HEMA. 


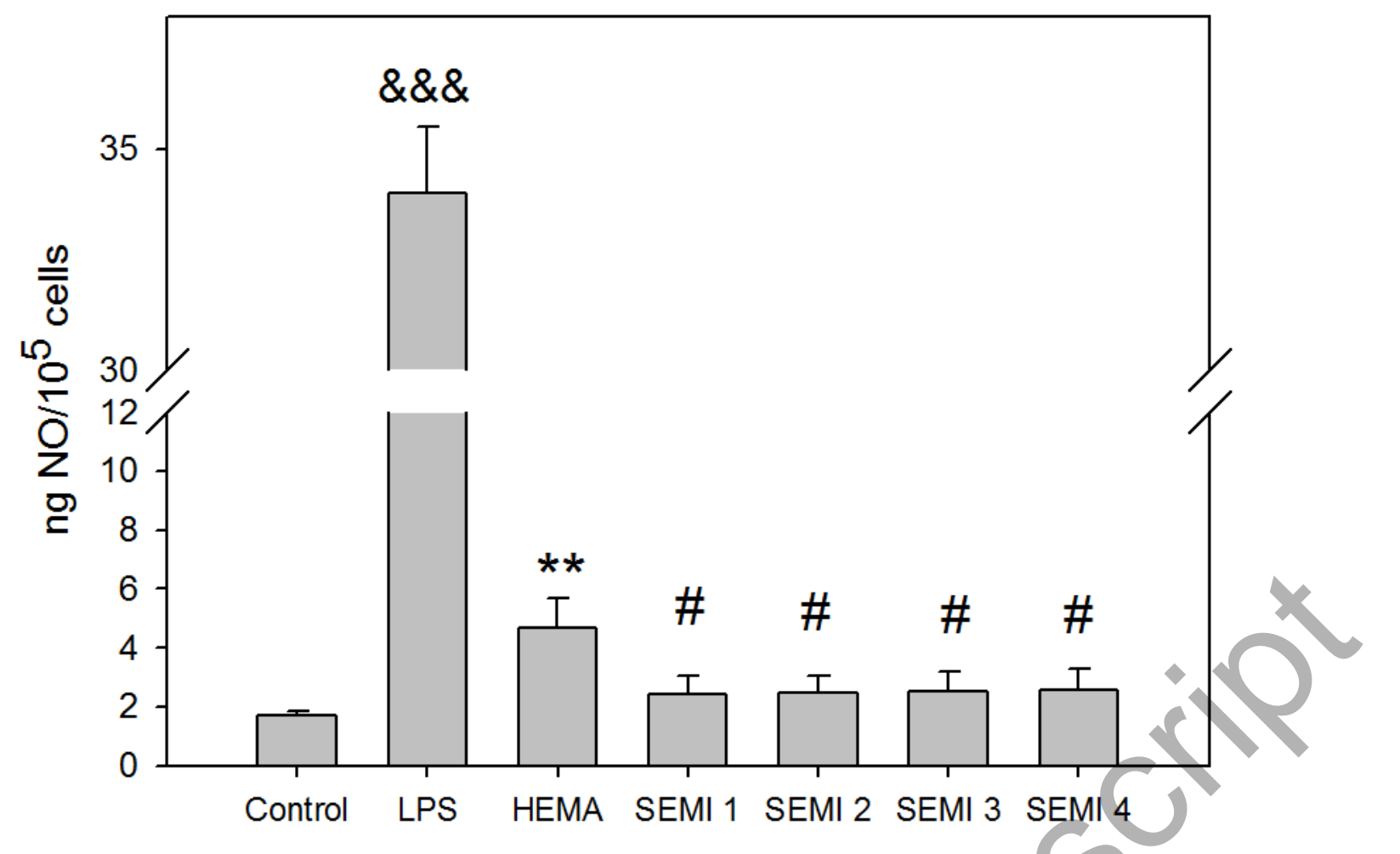

Fig. 6: NO production of RAW 264.7 cells grown over hydrogels and positive immunogenic control (LPS) and control (cells grown in dish culture). \#: $\mathrm{p}<0.05$ vs. HEMA; **: $\mathrm{p}<0.01$ vs. Control, $\& \mathrm{p}<0.001$ vs. control and all hydrogels. 

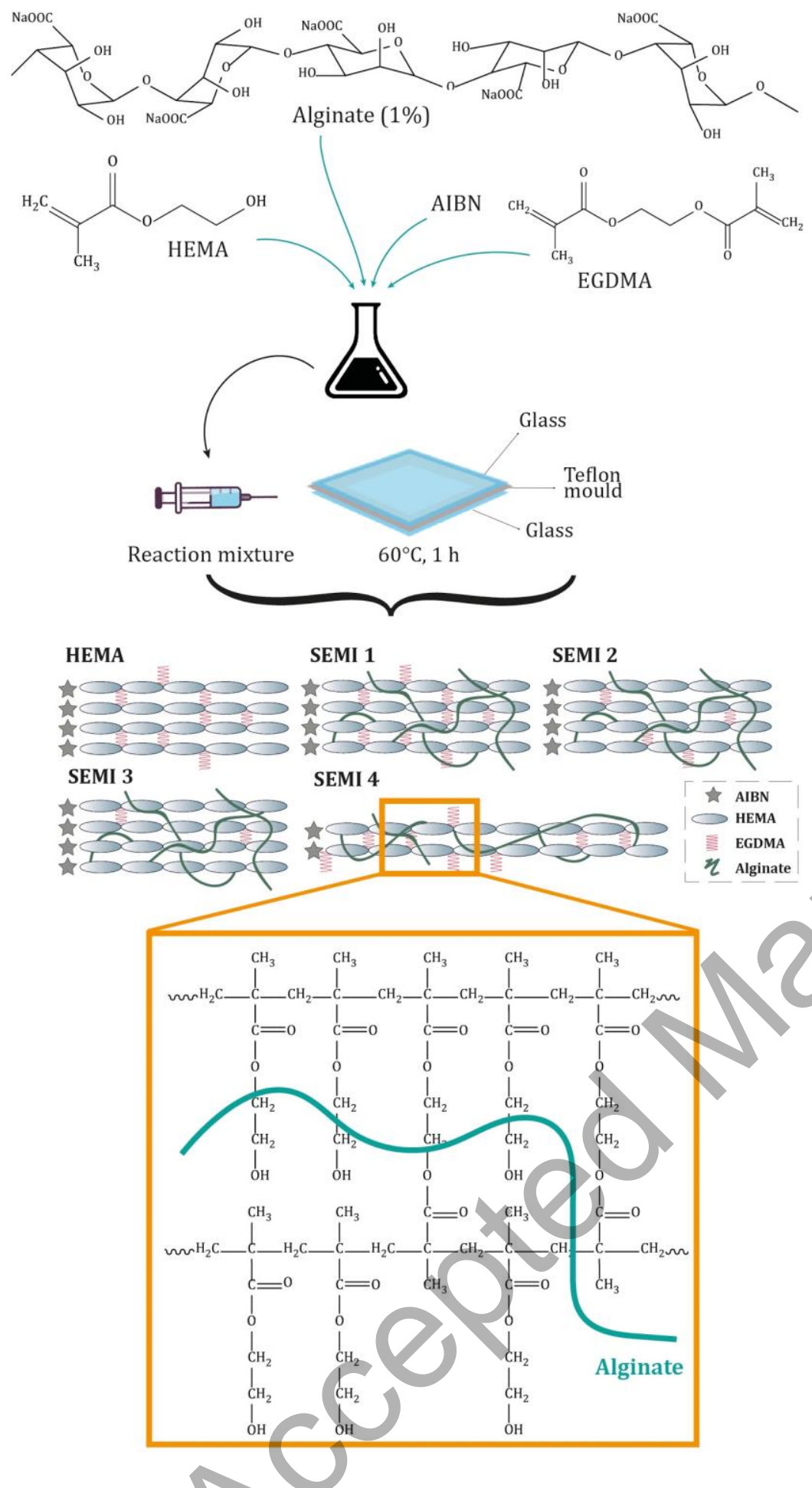

Scheme 1: scheme of synthesized hydrogels 